\title{
AVALIANDO A USABILIDADE DOS WEBSITES DE EDITORAS UNIVERSITÁRIAS BRASILEIRAS
}

\author{
Izabel França de Lima \\ Doutora em Ciência da Informação \\ Professora do Departamento de Ciência da Informação \\ Universidade Federal da Paraíba \\ belbib@gmail.com \\ Raphael Ferreira de Lima \\ Curso de Comunicação em Mídias Digitais \\ Universidade Federal Paraíba \\ raphael.ferreira.delima@gmail.com \\ Caroline da Silva Marinho \\ Curso de Biblioteconomia \\ Universidade Federal da Paraíba \\ carolinemarinhocsm@gmail.com \\ Héllida Gilliane de Medeiros Villar e Silva \\ Curso de Biblioteconomia \\ Universidade Federal da Paraíba \\ bmedeiros16@gmail.com
}

\begin{abstract}
Resumo
O presente artigo aborda a avaliação da usabilidade em websites de editoras universitárias das regiões Sul, Centro-Oeste e Norte do Brasil, trata-se de parte de uma pesquisa mais ampla, em andamento, com o objetivo de fomentar um estudo do panorama geral da situação dos websites das editoras universitárias no âmbito nacional. A metodologia empregada nesse estudo foi uma pesquisa quali-quantitava, com aplicação da metodologia para avaliação de usabilidade em ambientes digitais desenvolvida por Lima (2012). Os dados foram coletados nas páginas web de editoras universitárias, utilizando seus recursos de navegação. Os resultados estão expostos em gráficos para facilitar a apreciação, seguidos de análise de cada dos itens expostos, bem como de seus índices. Os resultados indicam uma insuficiência em atender de forma ideal as três frentes de estudo (eficiência, eficácia e satisfação), mas indicam que, de forma geral, os números apresentam um panorama positivo, demonstrando a contribuição das editoras universitárias das regiões Sul, Centro-Oeste e Norte do Brasil no meio em que se inserem.
\end{abstract}

Palavras-chave

Usabilidade. Editoras Universitárias. Acesso à informação. Satisfação do Usuário.

\section{INTRODUÇÃO}

A usabilidade é um termo muito amplo, ligado diretamente ao meio digital e relacionado também a aparelhos não eletrônicos. Ela pode ser aplicada a produtos como cafeteira, carrinho de supermercado, escovas de dente, caixas de atendimento bancário e a muitos outros produtos que precisaram ser estudados e pensados para um uso agradável e eficaz.

A usabilidade na web precisa gerar praticidade de uso. Medindo a capacidade de interação de um sistema com o usuário, sua aplicação busca adaptar a informação para que seja eficiente e efetiva.

A Internet é uma das Tecnologias de Informação e Comunicação (TIC) mais utilizadas no nosso cotidiano, por adentrar 
quase em todas as áreas do conhecimento e por manter uma relação estreita com a informação. Esse canal se mostra poderoso porque facilita bastante o acesso ao conhecimento, de maneira que o usuário não precise se locomover para obter o que procura, tendo mais comodidade para acessar todo tipo de conteúdo por computadores, tablets, celulares e qualquer tipo de dispositivo conectado à Internet.

Precisamos nos atentar para a usabilidade desses serviços e pensá-los como uma

[...] medida na qual um produto pode ser usado por usuários específicos para alcançar objetivos específicos com eficácia, eficiência e satisfação em um contexto de uso (ABNT, 2002, p. 3).

Nesse sentido, a usabilidade pode ser entendida como uma interface agradável em que o usuário se sinta confortável para realizar suas tarefas.

Dessa forma, é preciso levantar um método de avaliação que junte a necessidade dos usuários à satisfação proporcionada pelo site, para que este busque o conteúdo desejado e tenha uma experiência agradável em sua navegação. Um ambiente de navegação em que o usuário se sinta confortável para buscar, analisar, estudar e relacionar dados tanto quanto, ou melhor, que em um ambiente físico convencional.

Para além do campo técnico, o design do site também contribui para que a navegação seja satisfatória. Não adianta o site ter todos os aparatos tecnológicos se estes não são utilizados para facilitar o acesso à informação pelo usuário. Elementos gráficos, separação em blocos, hierarquia visual do site, contraste de cores, separação por nível e uma família tipográfica bem definida, entre outros recursos, contribuem para que o usuário obtenha uma experiência satisfatória sem mesmo perceber pela simplicidade da navegação.

Ponto levantado pela heurística de Nielsen (2007) é a promoção de estudos observacionais para compreender a real forma como o usuário usa a tecnologia, a fim de excluir possíveis respostas enviesadas de como ele crê que a usaria. Esta observação serve de referência através da observação de campo para termos certeza de que aquele público está conseguindo usar com satisfação o sistema, no intuito de trabalhar elementos do design sem entraves.

O presente artigo objetivou avaliar a usabilidade dos websites das Editoras Universitárias das regiões Sul, Centro-Oeste e Norte do Brasil com foco na eficácia, eficiência e satisfação. Busca-se contribuir com a construção de websites que melhor atendam às necessidades informacionais dos usuários/leitores.

O problema, quando se coloca em termos de pesquisa, assume relevância social, cultural, educacional e científica com repercussões na visibilidade da produção intelectual livresca das universidades brasileiras.

\section{USABILIDADE}

Dentre os inúmeros conceitos existentes na literatura especializada, entendemos a usabilidade como a capacidade de um produto ser facilmente usado e aprendido. Apesar de ser um conceito bastante ventilado entre profissionais de Internet e de mídia digital, é aplicável a produtos como aparelhos de DVD, brinquedos, cafeteiras, websites de comércio eletrônico e caixas de autoatendimento bancário, entre muitos outros.

Para avaliarmos a usabilidade de um produto existem três principais parâmetros: efetividade, eficiência e satisfação. Esses parâmetros devem ser avaliados em certo contexto de uso, levando-se em conta um grupo específico de usuários (LEÃO; SANTOS, 2007). Entretanto, para Nielsen (1998), a usabilidade está relacionada a cinco atributos do sistema: ser fácil de aprender, eficiente de usar, fácil de lembrar e agradável de usar, além de estar sujeito a poucos erros. Esta usabilidade está ligada à capacidade do sistema em interagir com o usuário, atendendo às suas necessidades, está relacionada à(s): facilidade de aprendizagem, 
efetividade, atitude, flexibilidade, utilidade percebida do produto, adequação à tarefa, características da tarefa e características do usuário.

Vários autores classificam a usabilidade de forma diferente. Nielsen e Loranger (2007) se referem à usabilidade como o quão rápido um usuário consegue aprender a usar algo, considerando os erros e o quanto aprecia utilizar aquilo. Se as pessoas não gostam, ou não conseguem realizar ações deste suposto produto, ele poderia muito bem nunca ter sido concebido, afinal não tem serventia.

Seguindo por uma linha de raciocínio semelhante, Ferreira e Souto (2006) dizem que as vias de navegação precisam ser claras para que o usuário não se confunda nem fique inseguro.

Percebemos assim uma tendência em que grande parte das definições apontam para a usabilidade como uma forma para solução do problema ou necessidade do usuário, de uma maneira que não o frustre nem provoque insatisfação em sua experiência de navegação.

\subsection{Avaliação de usabilidade}

Há algumas formas estabelecidas para tentar prever possíveis falhas na usabilidade. Segundo Pereira (2011), estes métodos se dividem em dois eixos: avaliações de viés analítico, que procuram respostas por meio de pesquisas com seus usuários; e avaliações empíricas, baseadas na observação da forma como esses interagem com seu sistema.

Num sentido mais amplo, Lima (2012) nos mostra a categorização de métodos de inspeção da aplicação e avaliação de usabilidade. Dentre eles, podemos considerar, para além da heurística, os métodos de:

a) inspeção baseada em guias de recomendação e guias de estilo: consiste em avaliar a usabilidade seguindo critérios especificados em um checklist que é completado com características desejadas no sistema avaliado. b) inspeção baseada em padrões: o sistema é avaliado seguindo os padrões estabelecidos vigentes. Seu intuito é que o sistema se adeque às convenções de usabilidade, para que o usuário consiga navegar nele sem problemas, se ancorando em outros sites que já navegou em sua experiência na Internet.

c) inspeção de percurso cognitivo: é criado um protótipo para simular a experiência real numa interface pronta. Geralmente sua prototipagem se dá em desenhos de papel, em que os avaliadores fazem o papel do sistema, respondendo as interações do usuário, ou em aplicativos como o Invision ${ }^{1}$, este último sendo mais utilizado no âmbito de aplicativos mobile.

d) inspeção de consistência: neste método prevalece a colaboração. Os membros de desenvolvimento de um conjunto de sistemas se reúnem para apontar erros e melhorias que poderiam contribuir para a finalização de um objetivo, tarefa ou cenário.

e) inspeção de componentes: este método estuda os componentes de uma determinada tarefa. O objetivo central se concentra em avaliar se os usuários conseguem compreender, executar e entender o objetivo de cada componente.

f) inspeção ou percurso pluralístico: reúne autoridades da área de usabilidade, projetistas do sistema e especialistas num processo inicial de desenvolvimento para avaliar a melhor forma de projetar o sistema, e então identificar as possíveis dificuldades que o usuário viria a ter. Consideramos este um método muito subjetivo, pois se baseia nas opiniões e experiências dos envolvidos.

\footnotetext{
${ }^{1}$ É uma ferramenta SaaS de prototipagem que ajuda o desenvolvimento de projetos de designs colaborativos
} 
g) inspeção de usabilidade formal: ocorre até mesmo no processo de desenvolvimento de um site ou sistema. Conhecido também como "fase de testes", nesta etapa pessoas externas à criação do projeto têm a função de encontrar bugs no sistema. A escolha de pessoas externas ao processo é necessária porque muitas vezes os criadores do sistema não conseguem perceber possíveis erros que podem ocorrer na sua implementação. Caso sejam percebidos erros no projeto, o mesmo retorna para equipe de desenvolvimento para correção e nova etapa de testes, até que o sistema tenha qualidade suficiente para ser disponibilizado para o usuário.

Ainda segundo Lima (2015), temos também as categorias de testes feitos com usuários. São eles:

a) testes empiricos de usabilidade: aplicado em ambiente controlado, este método visa à coleta de dados comportamentais dos usuários. Seu processo se dá através da observação, de forma a criar uma sequência exata de ações para realizar uma tarefa, assim evitando que o usuário perca tempo com atividades improdutivas.

b) entrevistas e questionários: os usuários são entrevistados ou recebem um questionário que busca compreender suas experiências, opiniões e preferências para criarem uma interface mais amigável (user-friendly) possível.

c) grupo focal: levanta as experiências e dificuldades dos usuários para avaliar a satisfação do sistema. Também são elencadas sugestões e opiniões que ajudem a solucionar problemas e melhorar o sistema para o usuário.

\subsection{Apresentando as categorias da avaliação de usabilidade}

No nosso contexto, considerando a metodologia de avaliação proposta por Lima
(2015), podemos segmentar os elementos do site para avaliarmos de forma separada. Dessa forma, se o site atende a todos os critérios propostos, ele atingirá um bom grau de usabilidade. As categorias foram divididas pelos segmentos de "Efetividade", "Eficiência", e "Satisfação", em cinco níveis de atendimento aos critérios para uma boa usabilidade, que vão de "Discordo fortemente" até "Concordo fortemente" e em pontos específicos que serão apresentados abaixo:

a) mantém o usuário sempre informado: consiste em notificar o usuário em mudanças na dinâmica do site, tanto no momento de uso quanto posteriormente: uma notificação de formulário que será perdido se trocar de página, uma notificação de mudança no site, inclusão de um livro, ou até mesmo um newsletter que permita que o usuário acompanhe as mudanças feitas na página. Newsletter é compreendida neste contexto como toda forma rotineira que a organização tem de se comunicar com o usuário via e-mail (WEB, 2009). Nielsen (2005) apresenta esse conceito como um retorno da página para o usuário em um prazo razoável.

b) controle do usuário nas ações: consiste em dar liberdade para o usuário navegar no site sem entraves, com tempo suficiente para utilizar o site sem que sua sessão expire com facilidade. Baseado na efetividade, trata-se da possibilidade de o usuário conseguir realizar suas ações de forma que não seja impedido pelo sistema ou tecnologia empregada no site. Nielsen (2005) incentiva o uso de recursos para desfazer e refazer a última ação do usuário, de forma que consiga manter o controle de sua navegação.

c) apresentação dos erros em forma: consiste na interação visual, sonora ou outro meio que permita o usuário identificar erros que ocorreram na página. Por exemplo: um formulário preenchido incorretamente, uma má 
comunicação com o servidor, uma opção necessária que não foi marcada, entre outras possibilidades que norteiem um caminho para $o$ usuário.

d) utilização da linguagem do usuário: consiste em segmentar os textos do site para uma linguagem comum entre todos, ou para a maioria do público que acessa aquela plataforma. A linguagem do usuário precisa estar alinhada com a linguagem do público ao qual se destina aquela comunicação.

e) padrão de navegação: o site apresenta um padrão de botões e ações em posicionamentos específicos em toda navegação.

f) ocorrência de erros: o site, para atender a este critério, deve ser livre de falhas de navegação. Não pode ter links que levem a lugar nenhum, botões que não executam nenhuma ação ou ações que provoquem o usuário a errar e ter que voltar à página anterior para esmiuçar a procura da ação desejada. Este conceito, apesar de parecer de responsabilidade exclusiva do programador do site, envolve questões mais simples, como a própria nomeação das ações e botões que precisa ser escolhida de forma que não levante dúvidas ao usuário (KRUG, 2014, p.12).

g) reconhecer objetos, ações e opções: o site deve ter seus elementos visíveis e acessíveis. É preciso que haja algum tipo de contraste, seja por posição, alinhamento, tipografia ou algum outro que consiga diferenciar os objetos (geralmente botões) e ações.

h) flexibilidade e eficiência de uso: algumas pessoas têm dificuldade de enxergar. Um site que possibilita o aumento das letras, um contraste melhor ou mecanismos que melhorem o site para diferentes públicos é mais flexível. No mesmo sentido, ele se torna mais eficiente por mais pessoas conseguirem executar suas ações, recursos esses tratados por Nielsen
(2005, p.1) como "aceleradores". Adentramos aqui no mérito do que se procura num site de editora: como publicar, como comprar, contato e catálogo de livros, entre outras, são informações relevantes que devem estar presentes na página.

i) estética e design: as pessoas não se sentem à vontade para navegar num site feio. $\mathrm{O}$ mais importante, de fato, é funcionar. Ter o que é procurado de maneira fácil e rápida. É como utilizar uma boa iluminação numa loja: as pessoas vão se interessar mais pelo seu produto.

j) ferramentas de ajuda: é preciso que, na página, seja possível chegar ao mesmo local de maneira eficaz, mesmo que essa não seja a melhor forma (KRUG, 2014). Essas ferramentas de ajuda, como um mecanismo de busca, um botão para aumentar a fonte, ou até um breadcrumb, utilitário que permite o usuário se localizar dentro do site, servem como auxílio ao usuário médio daquele site.

\section{A METODOLOGIA ADOTADA}

Neste artigo, optamos por uma abordagem quali-quantitativa. Sobre esta abordagem, Minayo e Souza (2005, p. 99) afirmam que

As aproximações quantitativas e qualitativas não devem ser consideradas antagônicas e sim linguagens complementares, embora de natureza diferente.

Neste sentido, com base na análise de Lima (2012) em artigos, pesquisas e dissertações nacionais e internacionais, com palavras-chave que encaixam diretamente com a proposta desta pesquisa, até mesmo por motivo de dar continuidade a um trabalho já iniciado, com foco nos websites das editoras universitárias do Nordeste e Sudeste, optamos por seguir o mesmo modelo de avaliação utilizado nos estudos anteriores, para também corroborarmos com 
a metodologia da tese, e, assim, contribuirmos para um panorama nacional da avaliação de usabilidade dos websites de editora universitárias.

Dito isto, no escopo deste artigo trataremos das editoras universitárias das regiões Sul, Centro-Oeste e Norte do Brasil, cadastradas no site da Associação Brasileira de Editoras Universitárias (ABEU), como parte de um banco de dados mais amplo que possa ser usado posteriormente em novas pesquisas a respeito de editoras universitárias nacionais.

Foram identificadas 50 editoras universitárias constantes no cadastro da ABEU nas regiões mencionadas. Dessas, 47 foram avaliadas pelo grupo de pesquisadores através das categorias apresentadas no quadro 1, que analisam a eficiência, eficácia e satisfação, com intuito de uma navegação mais rica, prática e sem ruídos na comunicação da interação humano-máquina.

Quadro 1 - Categorias de análise do instrumento de avaliação

\begin{tabular}{|l|l|}
\hline \multirow{4}{*}{ Efetividade } & Mantém o usuário sempre informado \\
\cline { 2 - 2 } & Controle do usuário nas ações \\
\cline { 2 - 2 } & Apresentação de erros em forma \\
\hline \multirow{4}{*}{ Eficiência } & Utilização da linguagem do usuário \\
\cline { 2 - 2 } & Padrão de navegação \\
\cline { 2 - 2 } & Ocorrência de erros \\
\cline { 2 - 2 } & Reconhecer objetos, ações e opções \\
\hline \multirow{3}{*}{ Satisfação } & Flexibilidade e Eficiência de uso \\
\cline { 2 - 2 } & Estética e Design \\
\cline { 2 - 2 } & Ferramentas de ajuda \\
\hline
\end{tabular}

Fonte: adaptado de Lima (2012, p. 105).

A avaliação de usabilidade se deu com aplicação das categorias de análise apresentadas por Lima (2012) nos websites contemplando como descrito a seguir:

a) definindo pontos a serem analisados utilizando o plano de atividades desenvolvido com base nas categorias apesentadas no Quadro 1, dividindo as atividades em três efetividade, eficiência e satisfação; b) visitando os websites das editoras e avaliando com base nas categorias citadas; c) analisando comparativamente os resultados.

Os dados foram coletados pelos pesquisadores aplicando o plano de atividade nos websites das editoras pesquisadas.

No Quadro 2 apresentamos as editoras universitárias das regiões Sul, Centro-Oeste e Norte constantes no site da ABEU. Foram analisados, no total, 47 websites, pois três inexistiam.

Quadro 2 - Editoras universitárias pesquisadas

(continua)

\begin{tabular}{|l|l|l|l|}
\hline $\mathbf{N}^{\mathbf{0}}$ & \multicolumn{1}{|c|}{ Editora } & \multicolumn{1}{|c|}{ Universidade } & \multicolumn{1}{|c|}{ Website } \\
\hline 1 & ARGOS & $\begin{array}{l}\text { Universidade Comunitária da Região } \\
\text { de Chapecó - Unochapecó }\end{array}$ & $\begin{array}{l}\text { http://www.editoraargos.com.br/farol/edi } \\
\text { toraargos/ }\end{array}$ \\
\hline 2 & EDIFURB & $\begin{array}{l}\text { Fundação Universidade Regional de } \\
\text { Blumenau }\end{array}$ & $\begin{array}{l}\text { http://www.furb.br/web/1456/multimidi } \\
\text { a/editora/apresentacao }\end{array}$ \\
\hline 3 & EDIPUC & $\begin{array}{l}\text { Pontifícia Universidade Católica do } \\
\text { Rio Grande do Sul }\end{array}$ & $\begin{array}{l}\mathrm{http} / / \text { www3.pucrs.br/portal/page/portal } \\
\text { /edipucrs/Capa }\end{array}$ \\
\hline 4 & EDITFURG & Universidade Federal do Rio Grande & http://www.edgraf.furg.br/ \\
\hline 5 & EDITORA CDB & Centro Dom Bosco & https://editora.centrodombosco.org \\
\hline 6 & $\begin{array}{l}\text { EDITORA DA } \\
\text { UFRGS }\end{array}$ & $\begin{array}{l}\text { Universidade Federal do Rio Grande } \\
\text { do Sul }\end{array}$ & http://www.ufrgs.br/editora/ \\
\hline 7 & $\begin{array}{l}\text { EDITORA DA UL- } \\
\text { BRA }\end{array}$ & $\begin{array}{l}\text { Universidade Luterana do Brasil } \\
\text { http://www.editoraulbra.com.br/ }\end{array}$ \\
\hline
\end{tabular}

Fonte: dados da pesquisa (2017). 


\begin{tabular}{|c|c|c|c|}
\hline $\mathbf{N}^{\mathbf{o}}$ & Editora & Universidade & Website \\
\hline 8 & EDITORA UFPEL & Universidade Federal de Pelotas & http://wp.ufpel.edu.br/editoraufpel/ \\
\hline 9 & EDITORA UNIJUI & $\begin{array}{l}\text { Universidade Regional do Noroeste } \\
\text { do Estado do Rio Grande do Sul }\end{array}$ & http://www.unijui.edu.br/editora-unijui \\
\hline 10 & $\begin{array}{l}\text { EDITORA UNISI- } \\
\text { NOS }\end{array}$ & $\begin{array}{l}\text { Universidade do Vale do Rio dos } \\
\text { Sinos }\end{array}$ & http://www.edunisinos.com.br/ \\
\hline 11 & EDIUNESC & $\begin{array}{l}\text { Universidade do Extremo Sul Cata- } \\
\text { rinense }\end{array}$ & $\begin{array}{l}\text { http://www.unesc.net/portal/capa/index } \\
/ 300 / 5860 /\end{array}$ \\
\hline 12 & EDIUNIARP & Universidade Alto Vale do Rio do Peixe & $\begin{array}{l}\text { http://www.uniarp.edu.br/home/a- } \\
\text { uniarp/editora-uniarp/ }\end{array}$ \\
\hline 13 & EDUA & Universidade Federal do Amazonas & http://www.edua.ufam.edu.br/ \\
\hline 14 & EDUCAT & Universidade Católica de Pelotas & http://educat.ucpel.edu.br/ \\
\hline 15 & EDUCS & Universidade de Caxias do Sul & https://www.ucs.br/site/editora/ \\
\hline 16 & EDUEFPA & Universidade do Federal do Pará & http://www.ufpa.br/editora/ \\
\hline 17 & EDUEPA & Universidade do Estado do Pará & https://paginas.uepa.br/eduepa \\
\hline 18 & EDUFAC & Universidade Federal do Acre & http://www.ufac.br/editora \\
\hline 19 & EDUFGD & $\begin{array}{l}\text { Universidade Federal da Grande } \\
\text { Dourados }\end{array}$ & https://portal.ufgd.edu.br/setor/editora \\
\hline 20 & EDUFMT & $\begin{array}{l}\text { Universidade Federal de Mato Gros- } \\
\text { so }\end{array}$ & http://www.editora.ufmt.br/ \\
\hline 21 & EDUFRA & $\begin{array}{l}\text { Universidade Federal Rural da Ama- } \\
\text { zônia }\end{array}$ & http://www.portaleditora.ufra.edu.br/ \\
\hline 22 & EDUFSC & $\begin{array}{l}\text { Universidade Federal de Santa Cata- } \\
\text { rina }\end{array}$ & http://editora.ufsc.br/ \\
\hline 23 & EDUNISC & Universidade de Santa Cruz do Sul & $\begin{array}{l}\text { http://www.unisc.br/pt/home/editora/p } \\
\text { ublicacoes/livros }\end{array}$ \\
\hline 24 & IFC & Instituto Federal Catarinense & http://www.ifceditora.com.br/ \\
\hline 25 & INTERSABERES & $\begin{array}{l}\text { Centro Universitário Internacional } \\
\text { UNINTER }\end{array}$ & http://www.intersaberes.com/ \\
\hline 26 & METODISTAIPA & $\begin{array}{l}\text { Centro Universitário Metodista - } \\
\text { IPA }\end{array}$ & $\begin{array}{l}\text { http://ipametodista.edu.br/pos- } \\
\text { graduacao/pesquisa/editora }\end{array}$ \\
\hline 27 & PUCPR & $\begin{array}{l}\text { Pontifícia Universidade Católica do } \\
\text { Paraná }\end{array}$ & $\begin{array}{l}\text { http://www.editorachampagnat.pucpr.br/i } \\
\text { ndex.php?idioma=pt_BR }\end{array}$ \\
\hline 28 & UDUEL & Universidade Estadual de Londrina & http://www.eduel.com.br/ \\
\hline 29 & UDUEM & Universidade Estadual de Maringá & http://www.eduem.uem.br/novapagina/ \\
\hline 30 & UDUEPG & $\begin{array}{l}\text { Universidade } \text { Estadual de } \text { Ponta } \\
\text { Grossa }\end{array}$ & http://www.uepg.br/editora/ \\
\hline 31 & UEG & Universidade Estadual de Goiás & http://www.editora.ueg.br/ \\
\hline 32 & UEMS & $\begin{array}{l}\text { Universidade Estadual de } \text { Mato } \\
\text { Grosso do Sul }\end{array}$ & http://www.uems.br/editora \\
\hline 33 & UFIBE & $\begin{array}{l}\text { Instituto Superior de } \\
\text { Berthier }\end{array}$ & $\begin{array}{l}\text { http://ifibe.edu.br/editora/catalog/index. } \\
\text { php }\end{array}$ \\
\hline 34 & UFMS & $\begin{array}{l}\text { Universidade Federal de Mato Gros- } \\
\text { so do Sul }\end{array}$ & http://www.editora.ufms.br/ \\
\hline 35 & UFMS & Universidade Federal de Santa Maria & https://editoraufsm.com.br/ \\
\hline 36 & UFPEDITORA & Universidade de Passo Fundo & http://editora.upf.br/ \\
\hline 37 & UFPR & Universidade Federal do Paraná & http://www.editora.ufpr.br/portal/ \\
\hline 38 & UNB & Universidade de Brasília & http://www.editora.unb.br/ \\
\hline 39 & UNICENTRO & $\begin{array}{l}\text { Universidade Estadual do Centro- } \\
\text { Oeste do Paraná }\end{array}$ & http://www3.unicentro.br/editora/ \\
\hline 40 & UNILASALLE & Universidade La Salle & $\begin{array}{l}\text { http://unilasalle.edu.br/canoas/editora-la- } \\
\text { salle }\end{array}$ \\
\hline 41 & UNIOESTE & $\begin{array}{l}\text { Universidade Estadual do Oeste do } \\
\text { Paraná }\end{array}$ & http://www.unioeste.br/edunioeste/ \\
\hline 42 & UNIRITTER & Laureate International Universities & https://www.uniritter.edu.br/editora/ \\
\hline
\end{tabular}

Fonte: dados da pesquisa (2017). 


\begin{tabular}{|l|l|l|l|}
\hline $\mathbf{N}^{\mathbf{0}}$ & \multicolumn{1}{|c|}{ Editora } & \multicolumn{1}{c|}{ Universidade } & \multicolumn{1}{c|}{ Website } \\
\hline 43 & UNISUL & $\begin{array}{l}\text { Universidade do Sul de Santa Catari- } \\
\text { na }\end{array}$ & http://www.editora.unisul.br/ \\
\hline 44 & UNIVALI & Universidade do Vale do Itajaí & http://siaiapp28.univali.br/ \\
\hline 45 & UNIVILLE & Universidade da Região de Joinville & http://www.univille.edu.br/ \\
\hline 46 & URIFW & $\begin{array}{l}\text { Universidade Regional Integrada do } \\
\text { Alto Uruguai e das Missões }\end{array}$ & http://www.fw.uri.br/site/pagina/editora \\
\hline 47 & UTFPR & $\begin{array}{l}\text { Universidade Tecnológica Federal do } \\
\text { Paraná }\end{array}$ & http://www.utfpr.edu.br/editora \\
\hline 48 & PUC GOIAIS & $\begin{array}{l}\text { Pontifícia Universidade Católica de } \\
\text { Goiás }\end{array}$ & SITE INEXISTENTE \\
\hline 49 & UNOPAR & Universidade do Norte do Paraná & SITE INEXISTENTE \\
\hline 50 & UNISALLES & Faculdade Salesiana de Vitória & NÃO POSSUI SITE PROPRIO \\
\hline
\end{tabular}

Fonte: dados da pesquisa (2017).

Os resultados da análise estão expostos nos gráficos do capítulo a seguir.

\section{RESULTADO E DISCUSSÃO}

Os websites foram analisados com base nas categorias de análise expostas no Quadro 1. Já no Quadro 2 apresentamos as editoras universitárias pesquisadas.

Os resultados estão organizados nos três principais eixos de avaliação, efetividade, eficiência e satisfação.

Gráfico 1 - Mantém o usuário sempre informado
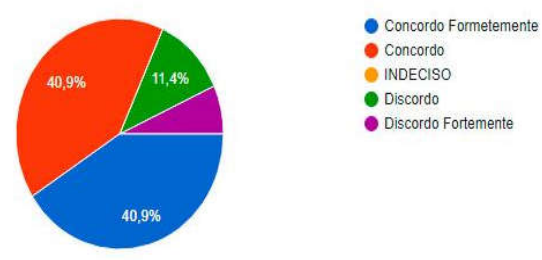

Fonte: Dados da pesquisa (2017).

No Gráfico 1 notamos que, entre as editoras analisadas, somente $9.1 \%$ (4 editoras) atendem ao critério. Um site sem retorno para o usuário não demonstra segurança para entender que está prosseguindo no caminho certo da informação que procura. Segundo Nielsen (2005), este recurso é importante para notificar o usuário do atual status do sistema.
Gráfico 2 - Controle do usuário nas ações
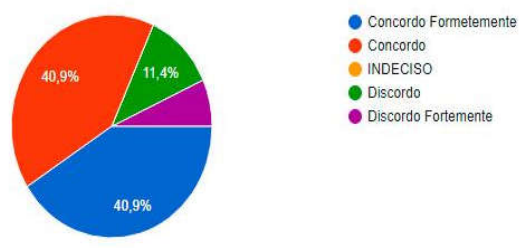

Fonte: Dados da pesquisa (2017)

Nielsen (2005) afirma que ações como "desfazer" e "refazer" são importantes, pois o usuário cometerá erros, mas estes devem ser facilmente solucionados. No Gráfico 2, "Concordo" e "Concordo fortemente" somam $81,8 \%$, o que indica que os sites das editoras universitárias adotam formas que agilizam a navegação de uma página à outra.

Gráfico 3 - Apresentação dos erros em forma

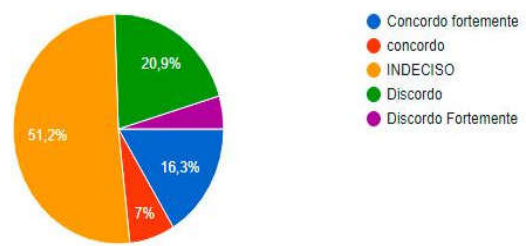

Fonte: Dados da pesquisa (2017).

Conforme Nielsen (2005, p.1), os sites precisam ter notificações, mensagens ou algum elemento em contraste com a página 
que alerte o usuário de erros. No Gráfico 3, notamos que apenas 16,3\%, um total de 7 entre as 44 editoras possíveis de análise, dão certeza de haver mensagens claras e objetivas para prevenir o usuário de errar.

Gráfico 4 - Utilização da linguagem do usuário

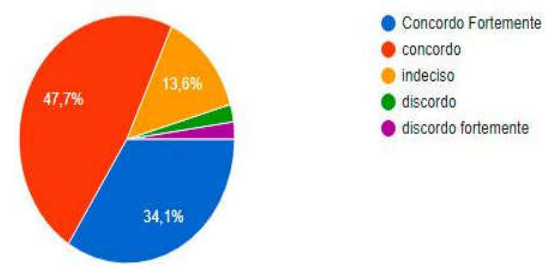

Fonte: Dados da pesquisa (2017).

O usuário precisa conseguir se comunicar com o sistema do site. Para que isto ocorra sem entraves, é necessário que ambos utilizem o mesmo tipo de linguagem (NIELSEN, 2005). Entre as editoras analisadas, $47,7 \%$ conseguem interagir com seu públicoalvo (Gráfico 4), que são geralmente pessoas ligadas à universidade, como estudantes, professores e técnicos. Vale lembrar que a "linguagem do usuário" é um termo subjetivo, uma vez que isto leva em consideração o público para o qual a página se destina.

Gráfico 5 - Padrão de navegação

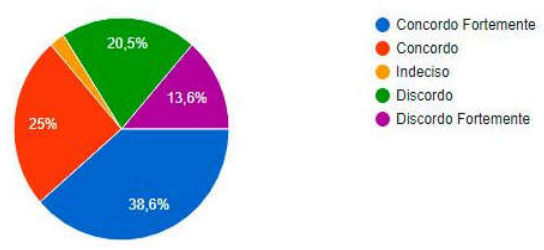

Fonte: Dados da pesquisa (2017).

Corroborando com Nielsen (2005), uma página com boa usabilidade não pode ter ações diferentes com um mesmo padrão visual. Isto é, menus, ações e botões precisam ser diferenciados. Neste sentido, elementos de mesma categoria com as mesmas formas, cores e posicionamentos facilitam o aprendizado do usuário na página. O Gráfico 5 indica que a maioria dos sites, $63,6 \%$ aplica convenções que, como trata Nielsen (2005, p.1), dão "consistência e padrão" à página.
Gráfico 6 - Ocorrência de erros
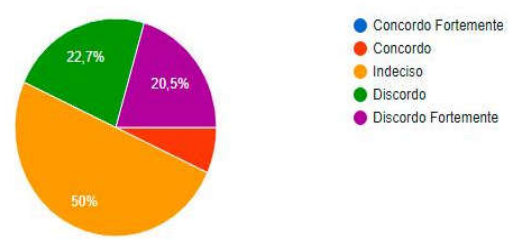

Fonte: Dados da pesquisa (2017).

$\mathrm{O}$ design cuidadoso previne que erros aconteçam, seja eliminando problemas em potencial ou confirmando ações com o usuário (NIELSEN, 2005). O Gráfico 6 revela que a maioria das editoras obteve um bom desempenho, com uma navegação com poucos erros e fluída.

\section{Gráfico 7 - Reconhecer ações, objetos e opções}
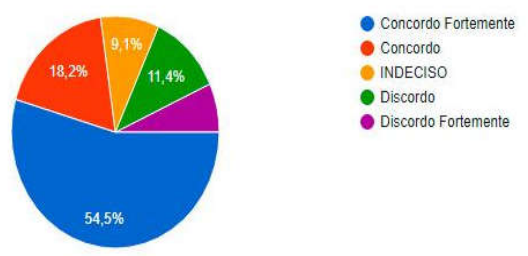

Fonte: Dados da pesquisa (2017).

No Gráfico 7 percebemos que a maioria dos sites promovem um bom reconhecimento dos elementos em seu site. Este fator é importante para que o usuário não precise memorizar para onde será direcionado cada caminho daquela navegação (NIELSEN, 2005). Salientamos que uma primeira navegação em um site com esta problemática requer mais tempo e mais esforço de memorização, enquanto uma solução simples e reconhecível pode ser acessada facilmente.

Gráfico 8 - Flexibilidade e eficiência de uso

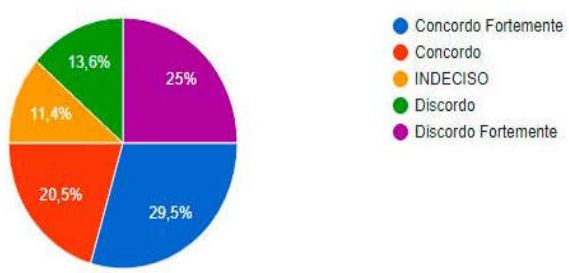

Fonte: Dados da pesquisa (2017).

Algumas pessoas têm dificuldade de enxergar os textos do site, outras são novatas 
e não encontram facilmente os mecanismos de navegação, pois não estão adaptadas com os mesmos. Um site que possibilita o aumento das letras, um contraste melhor ou mecanismos que melhorem o site para diferentes públicos, e mais de uma forma de chegar ao mesmo lugar é um site flexível. No mesmo sentido, o mesmo se torna mais eficiente por mais pessoas conseguirem executar suas ações, recursos esses tratados por Nielsen (2005, p.1) como "aceleradores". No Gráfico 8 percebe-se que metade das editoras se encaixa nas categorias "Concordo" e "Concordo fortemente", ou seja, apresentam mecanismos e recursos que facilitam a navegação do usuário.

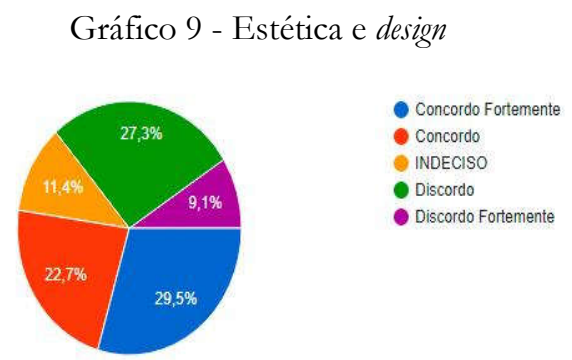

Fonte: Dados da pesquisa (2017).

Entre os sites analisados, apenas $29,5 \%$ trabalham competentemente as informações em sua página em termos de estética e design. Por outro lado, somente 9,1\% não atendem a este quesito, que envolve esquematização dos links, botões e a própria estética da página. Corroborando com Nielsen (2005, p.1): "cada informação extra numa página compete com elementos realmente relevantes". Desta forma, o minimalismo deve ser motivado e a informação bem aproveitada para ser repassada para o usuário sob demanda (KRUG, 2014).

Gráfico 10 - Ferramenta de ajuda

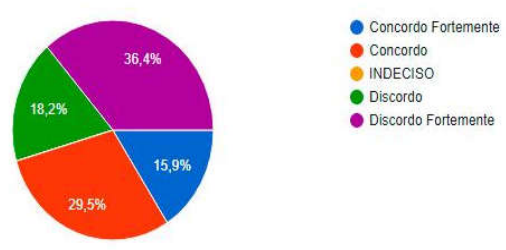

Fonte: Dados da pesquisa (2017).
Segundo Krug (2014), os usuários precisam chegar ao seu destino mesmo que esta não seja a maneira mais fácil e mais rápida. Analisando os resultados, notamos que $36,4 \%$ das editoras não oferecem ferramentas de ajuda suficientes para terceirizar as formas de acesso ao mesmo local do site. No mesmo sentido, remetendo a Nielsen (2005), um sistema deve conter instruções e documentação para acelerar a navegação do usuário, seja por meio de mecanismo de busca, aumento de fonte, breadcrumb para o usuário se localizar dentro do site e outros recursos.

\section{CONSIDERAÇÕES FINAIS}

De forma geral, tivemos um maior número de bons casos de usabilidade do que casos com problemas. Somente as categorias "Mantém o usuário informado", "Apresentação dos erros em forma" (efetividade), e "Ferramentas de ajuda" (satisfação) tiveram resultados de maioria negativa. Porém, vale lembrar que muito pode ser melhorado, pois notamos que a diferença entre os resultados negativos e positivos é irrisória, e um cenário ideal para a usabilidade seria todos os sites atenderem próximo $100 \%$ das características positivas do estudo.

Entre os três eixos da usabilidade abordados no estudo, eficiência foi o que obteve os melhores resultados mais favoráveis, tendo apenas a categoria "Ocorrência de erros" com um grande grau de indecisão, de quase $50 \%$, como item de maior ocorrência. Efetividade, no entanto, teve apenas o item "Controle do usuário nas ações" com bons índices.

Salientamos que a pesquisa pretende avaliar todas as editoras universitárias filiadas a ABEU, até o momento, o estudo foi aplicado no Nordeste e, em fase de conclusão, com as editoras universitárias do Sudeste brasileiro.

A partir dos resultados obtidos com a pesquisa nas regiões estudadas, consideramos que é preciso melhorar bastante a usabilidade dos sites de editoras universitárias brasileiras para se alcançar um patamar ideal, porém, a maioria das páginas 
estudadas cumpriu a função de forma satisfatória. Houve poucos casos de páginas com muita informação aglutinada, links quebrados ou incorretos e mudança na navegação na página, de encontro às heurísticas de Nielsen (2005, p.1). As páginas das editoras universitárias cadastradas no site da ABEU das regiões Sul, Centro-Oeste e Norte do Brasil cumprem seu propósito e estão sendo úteis e significantes para a construção e disseminação do conhecimento na universidade.

\title{
EVALUATING THE USABILITY OF BRAZILIAN UNIVERSITY EDITOR WEBSITES
}

\begin{abstract}
This article deals with the usability evaluation of university publishers' websites in the southern, central and northern regions of Brazil, in order to foster a study of the general situation of university publishers at the national level. The methodology used in this study was a qualitative-quantitative research, with application of the methodology for evaluation of usability in digital environments developed by Lima (2012). The data was collected on the main pages of university publisher sites and their navigation resources. The results collected from its quantitative stage are presented in graphs to facilitate the evaluation and later an analysis of each of the items exposed, as well as their indexes, finishing the qualitative analysis that composes the study. In the results evaluated, it was noticed that there was an insufficiency in attending to the three study fronts (efficiency, effectiveness and satisfaction), but it was noted that, in general, the figures present a positive outlook, demonstrating the contribution of university publishers in the southern regions, central west and north of Brazil, in the environment in which they are inserted.
\end{abstract}

Keywords

Usability. University publishers. Information access. User satisfaction. Artigo recebido em 27/12/2017 e aceito para publicação em 27/05/2018

\section{REFERENCIAS}

ABNT. NBR 9241-11: requisitos ergonômicos para trabalho de escritório com computador - Parte 11 - orientações sobre usabilidade. Rio de Janeiro, 2002.

CUNHA, M. B. Desafios na construção de uma biblioteca digital. Ciência da Informação, Brasília, DF, v.28, n.3, p. 257-268, set./dez. 1999. Disponível em:

$<$ http://www.scielo.br/pdf/ci/v28n3/v28n 3a3>. Acesso em: 15 fev. 2017.

DIAS, C. Usabilidade na Web: criando portais mais acessíveis. Rio de Janeiro: Alta Books, 2003.

ESTUDO sobre Web. Análise dos dados obtidos. A web 2.0. 2009.

FERREIRA, S. M. S. P.; SOUTO, P. C. N. A interface do usuário e as bibliotecas digitais. In: MARCONDES, C. H. et al. (Orgs.) Bibliotecas digitais: saberes e práticas. 2. ed. Salvador: UFBA; Brasília, DF: IBICT, 2006. p. 187-204.
KRUG, S. Não me faça pensar: atualizado: uma abordagem de bom senso à usabilidade web e mobile. Rio de Janeiro, RJ: Alta Books, 2014.

LEÃO, E.; SANTOS, R. A usabilidade e o caráter espacial do ciberespaço. Expressiva Comunicação e Educação, Rio de janeiro, 2007. Disponível em:

$<$ http:/ /www.expressivaonline.com.br/artig o.asp?idSelecionado $=21 \&$ idTema $=4>$.

Acesso em: 30 abr. 2017.

LIMA, I. F. Bibliotecas digitais: modelo metodológico para avaliação de usabilidade. 2012, 220f. Tese (Doutorado em Ciência da Informação) - Escola de Ciência da Informação, Programa de Pós-graduação em Ciência da Informação, Universidade Federal de Minas Gerais, 2012.

Bibliotecas digitais: modelo metodológico para avaliação de usabilidade. João Pessoa: Editora da UFPB, 2015.

MINAYO; M. C. S.; SOUZA, E. R. Métodos, técnicas e relações em triangulação. In: MINAYO; M. C. S.; ASSIS, S. G.; SOUZA, 
E. R. (Org.) Avaliação por triangulação de métodos. Rio de Janeiro: Fiocruz, 2005. Cap. 2, p. 71-103.

NIELSEN, J. Designing Websites with authority: secrets of an information architecture. Indianápolis: New Riders, 1998.

Ten usability heuristics. 2005.

Disponível em:

$<$ http://nptel.ac.in/courses/106103115/Ha ndouts/M4L4.pdf>. Acesso em: 10 nov. 2017.

.; LORANGER, H. Usabilidade na

Web: projetando websites com qualidade.

Rio de Janeiro: Elsevier, 2007.
PEREIRA, F. Avaliação de usabilidade em bibliotecas digitais: um estudo de caso. 2011, 122f. Dissertação (Mestrado em Ciência da Informação) - Escola de Ciência da Informação, Programa de Pós-graduação em Ciência da Informação, Universidade Federal de Minas Gerais, 2011. Disponível em:

<http://www.bibliotecadigital.ufmg.br/dspa ce/bitstream/handle/1843/ECID-

8LAKHD/dissertacao_pdf.pdf?sequence $=1$ >. Acesso em: 15 fev. 2017.

SEGAL, B. A short history of Internet protocols at CERN. 1995. Disponível em: $<$ http://ben.web.cern.ch/ben/TCPHIST.ht ml> Acesso em: 15 fev. 2017. 